\title{
Draft Surrogacy (Regulation) Bill 2016: Rhetoric or Surrogate-centric?
}

Dr. Rituparna Bhattacharyya ${ }^{\dagger}$

\section{Abstract}

Chaired by honourable Prime Minister, Mr. Narendra Damodar Modi, the Union Cabinet on 24 August 2016 introduced and approved the draft bill on Assisted Reproductive Technologies (ART) in India, known popularly as the Surrogacy (Regulation) Bill, 2016. The bill aims at regulating the ever-proliferating unregulated surrogacy industry interalia banning commercial surrogacy services for single parents, homosexuals, cohabiting partners in addition to foreigners and overseas citizens of India. The key aim of this commentary is to make a nuanced examination of the draft bill aimed at gaining a deeper understanding of the practice of surrogacy and address gaps (if any) that require interventions.

Key words: Assisted Reproductive Technologies, Surrogacy, Draft Surrogacy (Regulation) Bill 2016, India

\footnotetext{
${ }^{\dagger}$ Research Associate, School of Aeronautical, Automotive, Chemical and Materials Engineering Loughborough University, Leicestershire, UK LE11 3TU, Independent Researcher, Editor, Space and Culture, India and Training and Development, Alliance for Community Capacity Building in North East India

Email:rituparna.bhattacharyya@accb.org.uk

C2016 Bhattacharyya. This is an Open Access article distributed under the terms of the Creative Commons Attribution License (http://creativecommons.org/licenses/by/2.0), which permits unrestricted use, distribution, and reproduction in any medium, provided the original work is properly cited.
} 


\section{Introduction}

With the birth of the first test-tube baby, Louise Joy Brown on 25 July 1978 under the efforts of Robert Edwards and Patrick Steptoe, the invitro fertilisation (IVF) technique continues to claim ever-burgeoning demand all over the world (Rudrappa, 2015). Evidence suggests that over five million babies worldwide have been given birth using fertility treatment ${ }^{1}$ (MassyBeresford, 2014). In India, the first test-tube baby (second in the world) was born on 3 October 1978 through IVF under the supervision of Dr. Subhash Mukhopadhyay. However, professional jealousy and humiliation from his colleagues apace with public ostracisation and government apathy caused Dr. Subhash Mukhopadhyay to commit suicide out of dejection in 1981 (Bharadwaj, 2002; Chandra, 2011; Kumar, 1997). IVF technique did gain ground in the 1980s following the birth of the second test-tube baby in 1986 in Mumbai under Dr. Anand Kumar and Dr. Indira Hinduja (Bharadwaj, 2002; Rudrappa, 2015).

Health services (including ART services) became tradeable following the privatisation of India's health care "[u]nder the General Agreement in Trade in Services (GATS)" (Rudrappa, 2015: 38). Gradually, India emerged as a favourable destination of medical tourism especially for ART services (including surrogacy).

The word 'surrogate' originates from the Latin word surrogatus implying a substitute (Chandra, 2011). Surrogacy is a mode of outsourcing pregnancy, which obviously is a deviation from normal pregnancy demanding hierarchies of negotiations between the commissioning parents, doctors, surrogates and

\footnotetext{
${ }^{1}$ Fertility treatment uses Assisted Reproductive Technology (ART), which comprises of Intrauterine Insemination (IUI), In Vitro Fertilisation (IVF), Third Party Assisted ART (Sperm Donation, Egg Donation, Surrogates and Gestational Carriers)

(please see, Assisted Reproductive Technology (ART), US Department of Health and Human Services, National Institutes of Health, Eunice Kennedy Shriver national Institute of Child Health and Human Development. Retrieved from, https://www.nichd.nih.gov/health/topics/infertility/cond itioninfo/Pages/art.aspx
}

often the anonymous oocyte and sperm donors (Barua, 2016; Majumdar, 2014a, b; Rudrappa, 2015), thereby, transforming the outsourced pregnancy into a commercial contract. Elizabeth Kane, already a mother to three children is the world's first surrogate mother, who delivered her fourth baby (through surrogacy) on 9 November 1980 amidst stigma and taboo in the then American society of the late 1970s and early 1980s (Kane, 1980).

With the legalisation of commercial surrogacy in 2002, India transpired as the world's transnational surrogacy hub. There are approximately more than 3000 fertility clinics in India spread over places like Anand (Gujarat), Bengaluru (Karnataka), Mumbai, Delhi, etc., apparently, growing at $20 \%$ per annum, attributing a cost in between $\$ 35,000$ and $\$ 40,000$ per surrogacy service (Rudrappa, 2015; also, Bhattacharyya, 2016a).

A study conducted by the Centre for Social Research titled Surrogate Motherhood: Ethical or Commercial unravels that the surrogacy business is worth $\$ 500$ million, ${ }^{2}$ but "larger income shares go to the doctors and medical heads, and sometimes, the middlemen, leaving the surrogate mothers at the lowest level in the chain" (Bhattacharjee, 2016: 28; Thapa, 2012). In 2012, approximately 10,000 foreign tourists visited India for ART services of which nearly $30 \%$ were reckoned to have belonged to the queer-group or single parents (Rudrappa, 2015; also Bhattacharyya, 2016a).

Feminist Sandra Harding (1991), in her groundbreaking book-Whose Science? Whose Knowledge?: Thinking From Women's Lives, unravels as to how the rich and wealthy European and American couples hire the wombs of the Third World women for reproduction of children. Earlier, in 1985, Genea Corea argues and labels that the wombs of the women of the South as 'non-valuable' utilised for embryo-breeding for women of the North signalling and simultaneously

\footnotetext{
${ }^{2}$ Surrogate Motherhood-Ethical or Commercial, Centre for Social Research. Retrieved from, http://www.womenleadership.in/Csr/SurrogacyReport.p df
} 
questioning whether women of the South are simply baby-making machines in the name of commercial contracts. Notwithstanding, the problem of infertility is on the rise in India. It is estimated that currently, 22-33 million married couples of reproductive age suffer from the problem of lifetime infertility-while $30-40 \%$ of the males experience this problem, it is more among the females $(40-50 \%){ }^{3}$

Nonetheless, from the day commercial surrogacy was legalised, the Government of India have been keen to pass the Assisted Reproductive Technology (ART) Bill (2008, 2010 and 2013) versions (Rudrappa, 2015; Thapa, 2012). On 24 August 2016, under the chairpersonship of honourable Prime Minister, Mr. Narendra Damodar Modi, the Union Cabinet introduced and approved of the draft bill on Assisted Reproductive Technology (Regulation) Bill, ${ }^{4}$ which is popularly known as the Surrogacy (Regulation) Bill, $2016^{5}$ aimed at regulating the surrogacy services through prohibition of unethical practices. At the heart of the bill is a complete ban on commercial surrogacy including prohibition of "sale and purchase of human embryo and gametes". ${ }^{6}$ Once the draft bill is debated in the 2016 Winter Session of the Parliament to finalise; and passed by both the houses (Rajya Sabha or the Upper House and Lok Sabha or the Lower House) of the Parliament, India would be joining hands with the United Kingdom, China,

\footnotetext{
${ }^{3}$ Call for Action: Expanding IVF treatment in India (July 2015). Retrieved

from,http://www.ey.com/Publication/vwLUAssets/EYcall-for-action-expanding-ivf-treatment-in-

india/\$FILE/EY-call-for-action-expanding-ivf-treatmentin-india.pdf

${ }^{4}$ The Assisted Reproductive Technology (Regulation) Bill, Department of Health Research, Ministry of Health and Family Welfare, Government of India. Retrieved from, http://www.prsindia.org/uploads/media//draft/Draft\%2 0Assisted\%20Reproductive\%20Technology\%20(Regulatio n)\%20Bill,\%202014.pdf

${ }^{5}$ Cabinet approves introduction of the "Surrogacy (Regulation) Bill, 2016" (2016, 24 August), Press Information Bureau, Government of India Cabinet, Retrieved from, http://pib.nic.in/newsite/PrintRelease. aspx?relid=14918 6

${ }^{6}$ Please refer to footnote 5 .
}

France, Germany, Greece, Israel, Italy, Japan, Netherlands, Norway, Spain, Sweden and Switzerland that bans commercial surrogacy altogether (Armour, 2012). Arguably, the Surrogacy Bill 2016 aims to legalise altruistic surrogacy because commercial surrogacy, which was legalised in 2002, currently persists in a legal grey area without any legislative backing.

This commentary is an attempt to review the draft bill aimed at gaining a deeper insight into the practices of surrogacy and address gaps (if any) that require interventions.

\section{Bill Nomenclature}

The draft bill is a by-product of discussion with 18 ministries, 26 states, 40 stakeholders and various doctors wanting to communicate to the nation that commercial surrogacy is one of the illegal forms of business. It is a means to exploiting women (the surrogates) (Saravanan, 2010; Rudrappa, 2015; also Bhattacharyya, 2016a) who usually (but not necessarily) hail from poorer and vulnerable sections and are mostly from rural and tribal backgrounds. ${ }^{7}$ Arguably, commercial surrogacy is tantamount to commodification of women's bodies (Corea, 1985; Harding, 1991).

Except for the state of Jammu and Kashmir, the draft bill applies to the whole of India. The bill, as it stands now, neither lay the creation of a permanent structure, nor lays any intention of creating new posts but aims to establish "National Surrogacy Board at the central level and State Surrogacy Boards and Appropriate Authorities in the State and Union Territories." ${ }^{8}$ In addition, there are no financial implications laid down in the bill "except for the meetings of the National and State surrogacy Boards and Appropriate Authorities which will be met out

\footnotetext{
${ }^{7}$ Junior Health Minister Defends Controversial Surrogacy Bill (September 01, 2016). NDTV. Retrieved from, http://www.ndtv.com/video/shows/agenda/juniorhealth-minister-defends-controversial-surrogacy-bill429705

${ }^{8}$ Please refer to footnote 5 .
} 
of the regular budget of Central and State governments." ${ }^{\prime 9}$

\section{The Drivers of the Bill}

Although several high profile incidents and testimonies of conflict of interest and unethical practices (which I discuss below) have surfaced ever since commercial surrogacy was legalised in India, however, the 228th report of The Law Commission of India published almost seven years ago has been a key driver in advocating for allocation of ethical altruistic surrogacy for only those couples of Indian citizens who are really in need of the service (Bhattacharjee, 2016). At the same time, the 228th report also recommends outlawing commercial surrogacy through promulgation of a comprehensive Act. ${ }^{10}$ It is arguable that endorsement of ethical altruistic surrogacy for Indian citizens emanates from the ethos of Indian values embedded deeply within the patriarchal structures of the society where the status of a daughter-inlaw/wife is improved upon the birth of a child, more so, if the baby is a boy (Bhattacharyya, $2009 ; 2013)$. As the 228th report of The Law Commission of India (9) puts it:

The growth in the ART methods is recognition of the fact that infertility as a medical condition is a huge impediment in the overall wellbeing of couples and cannot be overlooked especially in a patriarchal society like India. A woman is respected as a wife only if she is mother of a child, so that her husband's masculinity and sexual potency is proved and the lineage continues. Some authors put it as follows: The parents construct the child biologically, while the child constructs the parents socially. The problem however arises when the parents are

\footnotetext{
${ }^{9}$ Please refer to footnote 5 .

${ }^{10}$ Law Commission of India (Report No. 228), August 2009. Need For Legislation to Regulate Assisted Reproductive Technology Clinics as Well as Rights and Obligations of Parties To a Surrogacy, Government of India. Retrieved from, http://lawcommissionofindia.nic.in/reports/report228.p df
}

unable to construct the child through the conventional biological means. Infertility is seen as a major problem as kinship and family ties are dependent on progeny. Herein surrogacy comes as a supreme saviour.

Against this backdrop, the features of the proposed bill are:

\section{Surrogacy is banned for foreigners (including Overseas Citizens of India)}

Evidently, over $80 \%$ of the children born from surrogate mothers are for foreign nationals, exemplifying largescale inequalities not only in economic terms but also in terms of class, race and nationalities between the surrogates and commissioning parents (Ghosh, 2016; Pande, 2009; 2011; Saravanan, 2010; Rudrappa, 2015). Because of these gendered power inequalities, the surrogates often face massive oppression and (or) unfair treatments-economically, physically and emotionally. It is also worth mentioning here that most surrogates, mired in multi-dimensional forms of poverty prefer foreigners to Indians for better payment (Bhattacharjee, 2016; Rudrappa, 2015).

A plethora of studies and news reports (Bhattacharjee, 2016; Saravanan, 2010; Rudrappa, 2015; also, Bhattacharyya, 2016a; Ghosh, 2016) suggest that women opting for surrogacies are expected to be highly submissive; arrogance and assertiveness are not tolerated. Once these women enter into the surrogacy contract, they are required to live in the surrogacy hostels or dormitories with other surrogates for the whole pregnancy period, separated from their families and child (ren). Evidence further suggest that if the surrogates fail to conceive or require termination (abortion) following miscarriage, ectopic pregnancy or foetal abnormality, then they are simply ask to leave the surrogacy premise without any financial compensation. Besides, the surrogates are required to go extensive painful process in their bodieshormone infusion (estrogen and progesterone) for preparation of the uterus, placement of embryo(s) in the surrogate's uterus, selective reduction (reduction of foetuses), most babies 
born through caesarean sections, emotional pains of relinquishing the baby they had birthed (Bhattacharjee, 2016; Majumdar, 2014a, b, c; Rudrappa, 2015; Saravanan, 2010; also, Bhattacharyya, 2016a).

In her world report on India's unregulated surrogacy industry published in the journal Lancet, Shetty (2012) unfolds that some fertility clinics of India implant up to five/six embryos in a surrogate's body, which is life-threatening bearing long-term biological implications on the surrogates' bodies leading not only to preeclampsia or gestational diabetes but also could damage organs like liver, kidneys and thyroid. Importantly, surrogates are paid only for one baby; often denied payment for delivering twins or triplets, or down syndrome babies; there are even incidences of delay in payments (Bhattacharjee, 2016; Rudrappa, 2015). Most importantly, these women receive no financial help should any complications arise in their post-pregnancy period following surrogacy.

Evidently, most surrogates with little or no education fail to understand the legal contract they sign. As the report-Surrogate Motherhood: Ethical or Commercial demonstrates that $88 \%$ surrogate participants in Delhi and $76 \%$ of Mumbai could seldom understand the clauses of the contract. There is also evidence to suggest that the commissioning parents often deal with the surrogates-laying conditions similar to purchasing a highly branded good/product (say, a car). As the Chapter III: Surrogate Mothers: 41 of the same report put it:

Experience shows that like any other commercial dealing the 'customer' lays down his/her conditions before purchasing the goods.

The surrogate may be forced to terminate the pregnancy if so desired by the contracting couple and she will not be able to terminate it if it is against the desire of the couple. She has difficulty in keeping her own baby. There have been instances where the contracting individual has specified the sex of the baby as well, refused to take the baby if it is not normal, and filed a suite against the surrogate saying she had broken the contract

The following narratives demonstrate that at times (and as witnessed), the atrocities against the surrogates and their babies are far more complex and entrenched indicating that the surrogates and the babies currently have no legal rights:

- Bhattacharjee (2016: 28) unravels that in 2015 , when a surrogate and her baby died in the delivery bed, the surrogate's family were not only devastated but also failed to receive any monetary compensation.

- In 2012 in Ahmedabad, Premila Vaghela, a surrogate suddenly died but the baby was saved through a caesarean section. What is saddening to note is that the commissioning American parents arrived in India quietly to adopt the baby and departed even more quietly (Desai, 2012; Majumdar, 2014a \& c).

- "They already had one sex and they didn't want the other child," Australian Family Court Chief Justice Diana Bryant told $\mathrm{ABC}^{11}$ That is, in 2012, an Australian couple refused to take home one of the twin siblings, born of an Indian surrogate based on the gender of the baby. This incident became known almost after two years.

- In late 2007, a Japanese couple Ikufumi and Yuki Yamada arrived at the Akanksha Infertility Clinic in Anand, Gujarat run by gynecologist Dr. Nayna Patel and signed a contract with the surrogate Mrs. Pritiben Mehta. However, in June 2008, prior to the birth of baby Manji, the commissioning parents divorced. Although, Ikufumi Yamada was keen to raise the baby but

\footnotetext{
${ }^{11}$ Australian couple reject surrogate baby in India on gender, take home its twin sibling (2014, 9 October). The Indian Express. Retrieved from, http://indianexpress.com/article/world/worldothers/australian-couple-reject-surrogate-baby-in-indiaon-gender-take-home-its-twin-sibling/
} 
Yuki Yamada refused. The crisis soon arose because baby Manji despite of having three mothers-the intended mother, the surrogate and the anonymous donor mother, whose eggs were harvested to produce an embryo using Ikufumi Yamada's sperm, the baby had to wait for months following citizenship issues as she was neither Indian nor Japanese. Finally, she was handed over to her 70-year-old grandmother Emkio Yamada (Pasayat, 2008; also, Bhattacharyya, 2016a).

- Similarly, in 2008, in the wake of these emerging assisted reproductive technologies, another challenge emerged in the same Akanksha Infertility Clinic in Anand, Gujarat when a surrogate mother, Marthaben Immanuel Khristi gave birth to two twins-Nicolas and Leonard for a German couple (Susanne Anna Lohle and Jan Balaz) bearing German nationality but who worked in the United Kingdom and had their desire to settle in the United Kingdom. Therefore, they were required to obtain Visa from the Consulate of the United Kingdom in India. Since the babies were born in India, they had applied for Indian passports wherein they filled in Mr. Balaz's name as the biological father and surrogate mother's name in the mother's column. At the first instance, Regional Passport Office, Ministry of External Affairs, Government of India entertained them issuing passports [Passport Numbers G-8229646 and G8229647 respectively] but $\mathrm{Mr}$. Balaz immediately received an intimationcum-notice to surrender the passports on the ground that the babies were surrogate babies; Germany seemingly refused to recognise surrogacy. In late 2009, although, the honourable Apex Court heard the case; one-time exception was permitted by Central Adoption Resources Agency allowing the babies to be adopted by Mr. Balaz (through inter-country adoption process) in May 2010, thereby, the babies were made eligible for a German Visa (Mahapatra, 2010; also Bhattacharyya, 2016a). ${ }^{12}$

All these anecdotal evidence are high profile reported cases that grabbed media (both print and electronic) headlines. These cases could be precursor to digressing realities where innumerable cases could go unreported/undocumented for various reasons. These observations bear similarities to cases of violence against women (VAW) where large cases of VAW remains unregistered in police stations for fear, stigma, taboo, embarrassment, etc. (Bhattacharyya, 2015; 2016b). In this context, Anupriya Patel, the youngest minister in the honourable Prime Minister's Cabinet and the Minister of State for Health make the same argument as Genea Corea (1985) by questioning: Is woman a childproducing factory?

Another appalling development connects commercial surrogacy to missing girls and trafficking. Young and adolescent tribal girls from remote parts of India (such as North East India, Jharkhand, Chhattisgarh, etc.) are either kidnapped or trafficked and are coerced into the practices of surrogacy (in addition to bonded/domestic labour, organ trade, prostitution and forced marriage) especially in the metropolitan cities (Bhattacharyya, 2016c; Nair and Sen, 2004; Prakash and Vadlamannati, 2014; Sarkar, 2014; Roy, 2015; Varma, 2013). ${ }^{13}$ Although, further in-depth research is necessary in order to gain a deeper insight into the problem, nonetheless, trafficking of young children especially girls remains a grave concern (Bhattacharyya, 2016c).

\footnotetext{
${ }^{12}$ Jan Balaz Vs. Anand Municipality and 6 ors. - Court Judgment, Legal Crystal. Retrieved from, https://www.legalcrystal.com/case/747551/jan-balaz-vsanand-municipality-6-ors

${ }^{13}$ Office to Monitor and Combat Trafficking in Persons2016 Trafficking in Persons Report, India, U.S.

Department of State. Retrieved from, http://www.state.gov/j/tip/rls/tiprpt/countries/2016/25 8784.htm
} 
Therefore, in the face of these complex and emergent challenges (here, in commercial surrogacy), the country "require[s] new responses and new strategies at a practical level; [and] at an analytical level, they require re-examining old concepts and theoretical paradigms and developing new ones" (Mohanty, 2003: 518). Hence, it remains paramount to ban on commercial surrogacy including disavowing of the surrogate baby, exploitation of the surrogates, buying/export of human embryo-all are reckoned violations deemed as punishable for a 10-year jail term, in addition to a fine of ₹1 million (Bera and Doval, 2016). Therefore, the Cabinet aims to rely on altruistic surrogacy for larger interest of the society. In altruistic surrogacy, as proposed in the draft bill, it would be illegal for the commissioning parents to pay the surrogate except for paying of all the medical bills (including nutritional requirements) linked to surrogacy. In addition, the draft bill postulates for compulsory 'insurance cover' of the surrogates during the whole period of pregnancy, while extending the insurance cover for a stipulated time period of post-pregnancy (Dey, 2016). It remains unclear as to how long the post-insurance cover would remain valid for. It is clear nevertheless that a woman opting for altruistic surrogacy should have healthy child(ren) of her own yielding from her marriage and would be allowed to act as surrogate only once in her lifetime. The draft bill also warrants that not only all the infertility clinics should have valid registrations but also will be required keep medical records of surrogacy practices for 25 years after the birth of the surrogate child.

However, the question remains-would altruistic surrogacy prevent exploitation of women. Would there be any mechanism to monitor as to how the surrogacy service offered is altruistic or commercial? Although, the draft bill propounds that unmarried or childless women would be debarred from opting to surrogacy contracts, critics remain apprehensive and argues that banning commercial surrogacy would lead to a deeper exploitation of women "where rich families would misuse the system by impelling poorer relatives or maids to act as surrogates for them" (Bhattacharyya, 2016a: 2; Rao, 2015). Parikshit Tank, an ART consultant from Mumbai seemingly believes that banning of commercial surrogacy would plummet down the surrogacy service only by $5 \%$. He nevertheless believes that it would be difficult to find women on altruistic grounds. Dr. Nayna Patel, Akanksha Infertility Clinic, Anand, Gujarat (where the high profile cases of surrogacy surfaced for wrong reasons) reiterates similar opinions in an interview to NDTV (Taneja, 2016). Dr. Patel reacts:

This is a social issue. I have taken up at least 25 cases within the family where there has been give and take of money within the family. Someone gives a jewellery set, someone gives a car. Nobody gives service without expecting something. The choice becomes limited to find someone within the family as surrogate mother. If a sister doesn't have a uterus, the daughter-in-law of the house could be forced to become a surrogate for her. What about the social pressure that she will go through? (Taneja, 2016)

Obviously, these apprehensions cannot be ignored for the simple reason that placing red tape to making the paradigm of surrogacy process tougher for the Indian couples in need might drive the process underground (as it would be also illegal for the commissioning parents to seek a surrogate through an advertisement in the media) (Shetty, 2012). This could open a greater road to exploitation of the poor, needy and the vulnerable women (Bhandare, 2015; Shetty, 2012).

\section{Surrogacy Services are Banned for Married Couples with Children, Single Parents, Cohabiting and Homosexual Couples}

The draft bill mandates that only legally married Indian couples and that too for at least five years (aged 23-50 in the case of females and 26-55 for males) with proven infertility (either or both) but aspiring for biological child(ren) could only opt for altruistic surrogacy 
as their last option. However, it is not known, should one of the couples falling in this category suffer from life-threatening medical condition, despite being financially capable would be able to seek surrogacy service or not?

Notwithstanding the honourable Apex Court's endorsement on the norms of live-in relationships (Choudhary, 2015), the draft bill disallows cohabiting couples from taking surrogacy services. In addition, the draft bill is also incongruous to Chapter VIII, Clause no. 57 of the Juvenile Justice (Care And Protection Of Children) Act, 2015 that allows a single parent (or a divorced person on fulfilment of certain criteria) to adopt a child (Agarwal and Kumar, 2015), ${ }^{14}$ but the proposed anti-surrogacy draft bill rejects surrogacy services for single parents and married couples with surviving child(ren) \{except for in cases where the child(ren) is/are mentally/physically challenged or terminally ill\}. The logic behind prohibition of seeking surrogacy services by married couples with children stems from misuse of commercial surrogacy by Indian celebrities. Minister for External Affairs, Mrs Sushma Swaraj commented:

The bill allows surrogacy only for necessity, not for luxury or fashion as we have seen repeatedly ... Big celebrities who not only have one but two children, a son and a daughter, even they went ahead with surrogacy (Bera and Doval, 2016)

However, not all parents may want a surrogate child for luxury or fashion. What about those parents whose only child may have gone missing $^{15}$ (through kidnapping and trafficking)

\footnotetext{
${ }^{14}$ Albeit a "single male is not eligible to adopt a girl child" \{please see, The Juvenile Justice (Care And Protection Of Children) Act, 2015 (NO. 2 of 2016).Ministry of Law and Justice(Legislative Department). Retrieved from, http://www.indiacode.nic.in/acts-inpdf/2016/201602.pdf\}

${ }^{15}$ It is ironic to note that India has emerged as the land of missing children. The 2014 Nobel Laureate Kailash Satyathi's NGO, Bachpan Bachao Aandolan (BBA) or Save the Childhood Movement that have rescued 85376 children since 1980 argues that every hour, about seven children go missing, amounting to 100,000 children each
}

and remains untraceable; should these parents (who might fall outside age-category stated above and fail to bear children naturally) offer to seek altruistic surrogacy service following the need for another biological child-an aspiration to continue their lineage (progeny).

Further, the bill prohibits (as has been in existence since 2013) homosexual couples from taking surrogacy services (see also, Rudrappa, 2015). This is because in December 2013, the honourable Apex Court decriminalised homosexual (gay and lesbian) relationships by triggering Article 377 of the Indian Penal Code (IPC), 1860 (Singh, 2013). ${ }^{16}$ Perhaps, values of Indian culture as it stand now are not prepared to embrace homosexual and live-in relationship couples, thereby proscribing them from commissioning surrogacy services. While Anupriya Patel argues that a child needs a 'normal family' signalling 'heterosexual couple', Mrs. Sushma Swaraj stated:

We do not recognise homosexual or live-in relationships that are why they are not allowed to commission babies through surrogacy. It is against our ethos. $^{17}$

year, out of which, each year, approximately 30,000 remains untraced (please see, Supreme Court of India Directs Compulsory Registration of FIRs in All Missing Children Cases, Bachpan Bachao Andolan, Retrieved from,http://www.bba.org.in/?q=content/supreme-courtindia-directs-compulsory-registration-firs-all-missingchildren-cases).

16 Section 377 of IPC 1860 reads as "Unnatural offences. -Whoever voluntarily has carnal inter-course against the order of nature with any man, woman or animal, shall be punished with 1 [imprisonment for life], or with imprisonment of either description for a term which may extend to ten years, and shall also be liable to fine. Explanation.-Penetration is sufficient to constitute the carnal intercourse necessary to the offence described in this section." Section 377 in The Indian Penal Code, Central Government Act. Retrieved from, https://indiankanoon.org/doc/1836974/

${ }^{17}$ New Surrogacy Bill Bars Married Couples with Kids, NRIs, Gays, Live-ins, Foreigners (2016, 25 August). The Indian Express. Retrieved from, http://indianexpress.com/article/india/india-newsindia/surrogacy-bill-sushma-swaraj-married-couples-cannow-opt-homosexuals/ 


\section{Safeguarding the Rights of the Surrogates and the Babies}

As evidenced above, the crux of the draft bill has been to implement a statutory mechanism in order to safeguard the rights of the surrogates and the babies born out of them in addition to curbing malpractices entailed within the billion-dollar industry. The question here is why women offer surrogacy choices despite enough evidence of exploitation. In her research on women surrogates in a local agency, Creative Options Trust for Women (COTW) at Bengaluru, Karnataka, Rudrappa (2015: 78) states that:

They [the women) bec[o]me surrogate mothers not simply to put a roof over their heads or food on the table, because they already had that. They [are] not destitute. But they [are] desperate.

Seemingly, Meena, a surrogate mother argues:

With price rise making lives of poor families like us difficult, I have planned to utilise the money for my children's education. Why should I mop floors and earn $₹ 3,000$ a month when I am getting $₹ 3$ Lakh for this? (Taneja, 2016).

In response to women's conscious choices of taking up surrogacy contracts for better livesbetter education for their children, construct a house, etc. or lift themselves out of multidimensional forms of poverty, Anupriya Patel reacted that selling of wombs is not the option to earn a livelihood. She goes on to slam the families who uses their women's bodies to earn money. In doing so, she argues that in Indian society, which is deeply embedded in patriarchal structure, women have very 'little say' within their household-it is often the women's family that coerces them to opt for surrogacy contracts. Arguably, the surrogates face exploitation from both sides-the families and the commissioning agents-mediators, clinics and the intending parents. Indeed, the draft bill sends a message to the families, who encourages/coerces their women to rent their wombs for money.
The draft bill also seeks to protect the rights of the surrogate babies, which would be the same as that of a baby born through the natural process. This means that babies born out of surrogacy would be entitled to all legal rights as citizens of India including inheritance rights. In addition, they would also have a right to know their parentage.

\section{Limitations}

\section{No Maternity Leave}

Despite the draft bill being progressive and stringent, the bill fails to provide maternity leave for those working women who could potentially opt for altruistic surrogacy for their friends and families. Interestingly, The Maternity Benefit (Amendment) Bill, 2016, ${ }^{18}$ which was introduced and passed in the Rajya Sabha on 11 August 2016 makes provision of 12-week of leave for commissioning mothers, it fails to make leave provisions for the surrogates (Singh, 2016). I, therefore, urge upon the concerned ministries to revisit the maternity bill to incorporate paid maternity leave for those working women who would potentially offer surrogacy services before it is finally passed in the Lok Sabha in the 2016 winter session of the Parliament (Singh, 2016).

\section{Prevention of Sex-selective Abortion}

In 1994, Pre-natal Diagnostic Techniques (Regulation and Prevention of Misuse) (PNDT) Act $^{19}$ was promulgated and has been in operation since 1 January 1996. Nevertheless, sex-selective abortion remains rampant in India (Jha et al., 2011; Bhattacharyya, 2016d). Evidence shows that illegal abortion has developed into ₹100 million-industry, signalling that a girl child is aborted every 12 seconds (Varma, 2013; also Bhattacharyya, 2014). In its

\footnotetext{
18 Bill No. XLIII of 2016: The Maternity Benefit (Amendment) Bill, 2016, PRS Legislative Research. Retrieved from, http://www.prsindia.org/uploads/media/Maternity\%20B enefit/Maternity\%20Benefit\%20Bill,\%202016.pdf

${ }^{19}$ The Act bans prenatal sex discernment and prohibits female foeticide and overall misuse of sex-selective abortion (Pre-natal Diagnostic Techniques Act \& Rules). Retrieved from: http://chdslsa.gov.in/right_menu/act/pdf/PNDT.pdf.
} 
current form, the bill makes no mechanism to tackle and prevent sex-selective abortion should the intending parents want to abort the foetus carried by their surrogate woman because of its sex.

\section{Conclusion}

Although the key aim of the bill is to empower surrogate women and the babies born out of them by preventing exploitation entailed in the billion dollar baby-making industry, the bill currently in its embryonic form is rhetoric and draconian. Contrary to the claims made by the concerned ministry, the current form of the bill fails to serve the larger interest of the societyit is undemocratic in the sense that it fails to incorporate all sections of the society. Therefore, the bill requires rigorous logical discussion and debates to cater the needs and aspirations of the larger society, before it can be finally passed in the Parliament.

\section{References}

Agarwal, Smita and Kumar, Nishant (2015). The Juvenile Justice (Care And Protection Of Children) Act, 2015: A Review, Space and Culture, India, 3(3), 5-9, DOI: http://dx.doi.org/10.20896/saci.v3i3.16 5

Armour, Kim, L. (2012). An Overview of Surrogacy around the World: Trends, Questions and Ethical Issues. Retrieved from, http://www.familiesthrusurrogacy.com/ wpcontent/uploads/2015/12/Overview-ofSurogacy-Around-The-World.pdf

Barua, Mrinal (2016). Surrogacy Debate. Letters, Economic and Political and Weekly, Li (37), 4-5

Bera, Sayantan and Doval, Nikita (2016, 25 August). India Govt Moves to Ban Commercial Surrogacy. Live Mint. Retrieved from, http://www.livemint.com/Politics/iJaM ugwl57XmKANE1juUnO/Cabinet-clearsbill-on-surrogate-motherhood.html
Bhandare, Namita (2015, 2 November). Baby Makers and Big Brother. Live Mint. Retrieved from, http://www.livemint.com/Opinion/V18 7jXfwmYTcoxHgTpumMK/Baby-makersand-big-brother.html

Bharadwaj, Aditya (2002). Conception Politics: Medical Egos, Media Spotlights, and the Contest Over Test-tube Firsts in India. In Marcia C. Inhorn and Frank Van Balen (eds.). Infertility Around the Globe: New Thinking on Childlessness, Gender, and Reproductive Technologies. Berkeley: University of California Press, 315-333

Bhattacharyya, Rituparna (2016a). Discounted Life: The Price of Global Surrogacy in India, Gender, Place \& Culture, 1-2, DOI: 10.1080/0966369X.2016.1211585

Bhattacharyya, Rituparna (2016b). Street Violence Against Women in India: Mapping prevention strategies, Asian Social Work and Policy Review, 10 (3), 311-325, DOI:10.1111/aswp.12099

Bhattacharyya, Rituparna (2016c). Living with Armed Forces Special Powers Act (AFSPA) as Everyday Life, GeoJournal, 118, doi: 10.1007/s10708-016-9752-9

Bhattacharyya, Rituparna (2016d, 15 February). Sex of Foetus and Mandatory Registration. The Assam Tribune, page 6

Bhattacharyya, Rituparna (2015).

Understanding the Spatialities of Sexual Assault Against Indian Women in India. Journal Gender, Place and Culture. 22 (9), 1340-1356, DOI:10.1080/0966369X.2014.969684

Bhattacharyya, Rituparna (2014). Life and Times of Unborn Kamla, New Delhi: Palimpsest Publishers, Journal Space and Culture, India, 2(2), 57-58, DOI:

http://dx.doi.org/10.20896/saci.v2i2.89

Bhattacharyya, Rituparna (2013). Are We Empowered? Stories of Young Indian Working Women, Saarbrücken, Germany: Lap Lambert Academic Publishing, ISBN: 978-3-659-20580-4 
Bhattacharyya, Rituparna (2009). Examining the Changing Status and Role of Middle Class Assamese Women: Lessons from the Lives of University Students, PhD thesis, Newcastle University, UK

Bhattacharjee, Dalia (2016). Commercial Surrogacy in India Bans, 'Altruism' and the Women Involved, Economic and Political Weekly, LI (13), 27-29

Corea, Genea (1985). The Mother Machine: Reproductive Technologies from Artificial Insemination To Artificial Wombs, New York: Harper and Row

Chandra, Smith (2011, 16 February). Surrogacy and India: A Legal Perspective. Retrieved from, http://dx.doi.org/10.2139/ssrn.1762401

Choudhary, Amit Anand (2015, 24 July). Live-in Relationships Now Acceptable Norm in Society: SC. The Times of India.

Retrieved from, http://timesofindia.indiatimes.com/indi a/Live-in-relationships-now-acceptablenorm-in-societySC/articleshow/48195514.cms

Desai, Kishwar (2012, 5 June). India's Surrogate Mothers are Risking Their Lives. They Urgently Need Protection, The Guardian. Retrieved from, https://www.theguardian.com/commen tisfree/2012/jun/05/india-surrogatesimpoverished-die

Dey, Sushmi (2016, 24 August). Cabinet May Take Up Surrogacy Bill Today, The Times of India. Retrieved from, http://timesofindia.indiatimes.com/indi a/Cabinet-may-take-up-surrogacy-billtoday/articleshow/53835511.cms

Ghosh, Abantika (2016, 2 September). Surrogacy Legislation: Is Woman A Child-Producing Factory Asks Anupriya Patel, The Indian Express. Retrieved from, http://indianexpress.com/article/india/i ndia-news-india/surrogacy-ban- commercial-foreign-clients-womanchild-producing-machine-3008933/

Harding, Sandra (1991). Whose Science? Whose Knowledge?: Thinking from Women's Lives. Ithaca, NY: Cornell University Press

Jha Prabhat, Maya A Kesler, Rajesh Kumar, Faujdar Ram, Usha Ram, Lukasz Aleksandrowicz, Diego G Bassani, Shailaja Chandra and Jayant K Banthia (2011). Trends in Selective Abortions of Girls in India: Analysis of Nationally Representative Birth Histories From 1990 To 2005 And Census Data From 1991 to 2011, The Lancet, 377 (9781), 1921-1928

Kane, Elizabeth (1980, 8 December). Surrogate Mother Elizabeth Kane Delivers Her 'Gift of Love'-Then Kisses Her Baby Goodbye. People, 14 (23). Retrieved from, http://people.com/archive/surrogatemother-elizabeth-kane-delivers-her-giftof-love-then-kisses-her-baby-goodbyevol-14-no-23/

Kumar, Anand, T.C. (1997). Architect of India's First Test Tube Baby: Dr Subhas Mukerji (16 January 1931 to 19 July 1981), Current Science, 72 (7), 526-531

Massy-Beresford, Helen (2014, 23 November). What's Next for the World's 5 million IVF Babies, The Guardian. Retrieved from, https://www.theguardian.com/society/ 2014/nov/23/whats-next-for-worlds-5million-ivf-babies

Majumdar, Anindita (2014a). The Rhetoric of Choice: The Feminist Debates on Reproductive Choice in the Commercial Surrogacy Arrangement in India, Gender, Technology and Development, 18 (2), 275-301, DOI: $10.1177 / 0971852414529484$

Majumdar, Anindita (2014b). Nurturing an Alien Pregnancy: Surrogate Mothers, Intended Parents and Disembodied 
Relationships, Indian Journal of Gender Studies, 21(2), 199-224, DOI: $10.1177 / 0971521514525087$

Majumdar, Anindita (2014c, 7 October). The Anonymous Womb: The 'Construction' of the Surrogate Mother in the Indian Media, Stree Mukti Sangathan

Mahapatra, Dhananjay (2010, 27 May). German Surrogate Twins To Go Home, The Times of India. Retrieved from, http://timesofindia.indiatimes.com/indi a/German-surrogate-twins-to-gohome/articleshow/5978925.cms?referr al=PM

Mohanty, Chandra Talpade (2003). Under Western Eyes Revisited: Feminist Solidarity through Anticapilatist Struggles, Signs: Journal of Women in Culture and Society, 28(2), 499-535

Nair, P.M. and Sankar Sen (2004). A Report on Trafficking in Women and Children in India 2002-2003, NHRC-UNIFEM-ISS Project at 203. Retrieved from: http://nhrc.nic.in/Documents/Reporton Trafficking.pdf

Pande, Amrita (2009). "It May Be Her Eggs But It's My Blood": Surrogates and Everyday Forms of Kinship in India, Qual Sociol, 32, 379-397, DOI 10.1007/s11133-0099138-0

Pande, Amrita (2011). Transnational Commercial Surrogacy in India: Gifts for Global Sisters, Symposium: Cross-Border Reproductive Care Article, Reproductive BioMedicine Online, 23, 618-625

Pasayat, Arijit (2008, 29 September). Baby Manji Yamada vs Union Of India \& Anr on 29 September, 2008, Supreme Court of India. Retrieved from, https://indiankanoon.org/doc/854968/

Prakash, Nishith and Vadlamannati, Krishna Chaitanya (2014). Girls for Sale?Child Sex Ratio and Girls Trafficking in India, IZA Discussion Papers, No. 8293

Rao, R. Sunitha (2015, 13 November). Ban on Surrogacy Will Lead To Exploitation. The
Times of India. Retrieved from, http://timesofindia.indiatimes.com/city /bengaluru/Ban-on-surrogacy-will-leadto-

exploitation/articleshow/49763078.cms

Roy, Saurav (2015, 25 February). Trafficked Tribal Girls Forced To Conceive, Deliver Babies For Sale, Hindusthan Times. Retrieved from: http://www.hindustantimes.com/indianews/tribal-girls-forced-to-conceivedeliver-babies-for-sale/article11320239.aspx

Rudrappa, Sharmila (2015). Discounted Life: The Price of Global Surrogacy in India, New York and London: New York University Press

Saravanan, Sheela (2010). Transnational Surrogacy and Objectification of Gestational Mothers, Economic and Political Weekly, XLV (16), 26-29

Sarkar, Siddhartha (2014). Rethinking Human Trafficking in India: Nature, Extent and Identification of Survivors, The Round Table: The Commonwealth Journal of International Affairs, 103 (5), 483-495, DOI:10.1080/00358533.2014.966499

Shetty, Priya (2012). India's Unregulated Surrogacy Industry, World Report, The Lancet, 380, 1633-1634

Singh, Harmeet Shah (2013, 11 December). India's Supreme Court Declares Homosexual Sex Illegal, CNN. Retrieved from, http://edition.cnn.com/2013/12/11/wo rld/asia/india-same-sex-relationship/

Singh, Suman (2016). The Maternity Benefit (Amendment) Bill, 2016: A Critical Analysis, Space and Culture, India, 4(2), 22-28, DOI:http://dx.doi.org/10.20896/saci.v4i 2.210

Taneja, Richa (2016, 2 September). Pics: Top 10 Voices On The Debate On New Surrogacy Bill. NDTV: Every Life Counts. Retrieved from, 
http://everylifecounts.ndtv.com/debate -new-surrogacy-bill-top-10-voices-4527

Thapa, Jwala D (2012). Analysing the Status of the Surrogate Mother under The Assisted Reproductive Technologies (Regulation) Bill, 2010, NUJS Working Paper Series, The West Bengal National University of Juridical Sciences
Varma, K.K. (2013). Life and Times of Unborn Kamla, New Delhi: Palimpsest Publishers

\section{Acknowledgements}

I thank the reviewers for their valuable comments on an earlier draft of this review. I also thank Mr. Dhurjjati Sarma for copy-editing the manuscript. 